\title{
Filosofar desde os arquipélagos: filosofia afrodiaspórica como disputa de imaginários
}

\author{
Philosophy from the archipelagos: afro-diaspora philosophy as a dispute of \\ imaginaries
}

Luís Carlos Ferreira dos Santos*, Eduardo David de Oliveira*

\begin{abstract}
Resumo: O presente trabalho busca disputar imaginários a partir da compreensão de dois conceitos, arquipélagos e filopoética, em diálogo com o pensamento do ensaísta, filósofo e poeta Édouard Glissant. Ele é um pensador do arquipélago e, por isso, do todo-mundo. O pensamento da relação é a resposta oferecida por ele como caminho de superação e crítica à dominação monocolonialista. A obra de Glissant envolve tanto uma estética quanto uma política e mobiliza tanto uma filosofia quanto uma poesia. O diálogo da filosofia e a poesia se dá no intuito do primeiro criar conceitos e o segundo fecundá-lo de imaginação (filopoética).
\end{abstract}

Palavra-chave: Filopoética; Arquipélago; Imaginário; Filosofia afrodiaspórica

Summary: The present work seeks to dispute imaginaries based on the understanding of two concepts, archipelagos and filopoetics, in dialogue with the thought of the essayist, philosopher and poet Édouard Glissant. He is a thinker of the archipelago and, therefore, of the whole world. The thought of the relationship is the answer offered by him as a way of overcoming and criticizing monocolonialist domination. Glissant's work involves both aesthetics and politics and mobilizes both a philosophy and a poetry. The dialogue of philosophy and poetry takes place in the intention of the first to create concepts and the second to fecundate it of imagination (filopoetic).

Key-word: Filopoetic; Archipelago; Imaginary; Afro-Diaspora Philosophy

\section{Introdução}

Estar à deriva

$\mathrm{Na}$ linguagem.

\footnotetext{
* Doutor em Difusão do Conhecimento (UFBA); Mestre em Educação (UFBA); Graduado em Filosofia (UFBA); Membro do Grupo de Pesquisa Rede Africanidades.

${ }^{*}$ Professor da FACED/UFBA. Líder do Grupo de Pesquisa Rede Africanidades, Sócio-fundador do IPADInsituto de pesquisa da afrodescendência e sócio-fundador do IFIL - Insituto de Filosofia da Libertação e atualmente coordenador da Linha de Pesquisa Conhecimento e Cultura do Doutorado Multi-institucional, Multidisciplinar em Difusão do Conhecimento.
} 
Estar só

Em órbita.

Traído à vista

do mar: pela origem

a

ponto de trair

se tornar

um verbo

totem.

Esculpido

no mar

à revelia

de ti. ${ }^{1}$

Este artigo busca compreender a filopoética e o arquipélago presentes no pensamento de Édouard Glissant, no intuito de defender a filosofia desde o arquipélago como disputa de imaginários.

Édouard Glissant nasceu em vinte e um de setembro de 1928, na Martinica, e faleceu em três de fevereiro de 2011, em Paris. A provocação realizada pelo pensador dos arquipélagos explode o potencial de imaginação do seu leitor. A produção do martinicano percorre o exílio e a errância, porque explode o mesmo, entendido como transparência.

$\mathrm{O}$ artigo pretende trazer para o diálogo o ensaio poético de Glissant $O$ pensamento do tremor ${ }^{2}$, Poética da Relação ${ }^{3}$ e o ensaio filosófico Philosophie de la Relation: poésie en étendue ${ }^{4}$. A discussão da filopoética toma como referência Manuel Norvat em Le Chant du Divers. Introduction à la philopoétique d'Édouard Glissant ${ }^{5}$. O conceito de filopoética não é cunhado por Glissant, no entanto, percorre seu pensamento.

Édouard Glissant é um pensador do arquipélago e, por isso, do todo-mundo. A violência do presente e o choque do passado (monocolonialismo), movimentaram as produções deste intelectual contemporâneo. O pensamento da relação é a resposta oferecida por Glissant como caminho de superação e crítica à dominação monocolonialista. A perspectiva de crítica à violência monocolonialista é agenciada por meio da relação tanto da estética quanto da política e mobiliza a filosofia e a poesia.

\footnotetext{
${ }^{1}$ PEREIRA, E, p.11.

${ }^{2}$ GLISSANT, O pensamento do tremor. La cohée du Lamentin, 2014.

${ }^{3}$ GLISSANT, Poética da Relação, 2011.

${ }^{4}$ GLISSANT, Philosophie de la Relation: poésie en étendue, 2009.

${ }^{5}$ NORVAT, Le Chant du Divers. Introduction à la philopoétique d'Édouard Glissant, 2015.
} 
A estética, a política e a ética, em Glissant, estão na direção da ruptura da identidade raiz, a qual congela e violenta o diverso. O diálogo se dá na criação de conceitos, fecundando-o de imaginação (filopoética). A criação de conceito é um passo necessário no filosofar, mas fecundá-lo de imaginação é um salto crítico e criativo nos arquipélagos.

A provocação realizada por Glissant estabelece a necessidade de outras paisagens na lógica de filosofar. A filosofia africana que é múltipla e diversa em sua abordagem e no seu conteúdo é um leitmotiv para este modo de produzir e disputar mundos. O movimento unitário e totalitário de defender uma filosofia universal, sem contexto, tem uma produção de sentido o qual legitima um imaginário conservador e produtor de necropoder ${ }^{6}$. Ao partir desde uma filosofia em arquipélagos se tem como princípio o diverso do mundo, mas reconectado com as suas paisagens, é uma produção filosófica em relação, na disputa pelo imaginário do mundo.

A guerra dos imaginários é um desejo obstinado por se reinventar em um país dominado pelo racismo. "Devo me lembrar, a todo instante, que o verdadeiro salto consiste em introduzir a invenção na existência”. ${ }^{7}$

\section{Filosofar em arquipélagos ${ }^{8}$}

O arquipélago é o que possibilita a multiplicidade, consequentemente, a possiblidade da relação com o “Todo-mundo". Para adentrar no entendimento da filopoética é importante o entendimento do arquipélago, pois este marca a perspectiva do diverso em sua disputa pela criação dos imaginários.

$O$ arquipélago diferencia-se do conceito de continente e de ilha, não tem a perspectiva de sínteses impostas como o continente e tampouco uma ilha isolada, mas um conjunto de ilhas. O arquipélago evidencia um dos pontos importantes da sua construção poética, filosófica e do seu engajamento político: o espaço. O arquipélago neste aspecto não tem a característica do relativismo exacerbado, como a ilha isolada, nem do totalitarismo, como das sínteses impostas dos continentes. $O$ arquipélago mobiliza-se pelos contrastes.

Umas das características das ilhas foram ser marcadas pelo pensamento do continente. A grande extensão dessas ilhas permitiu as retiradas da luta, os reagrupamentos maciços, tendo como consequência a emergência de um espírito nacional, o aparecimento de um campesinato decisivo. A segunda característica do arquipélago

\footnotetext{
${ }^{6}$ MBEMBE, Necropolítica, 2018.

${ }^{7}$ FANON, Pele Negra, Máscara Brancas, p.189.

8 O conceito de arquipélago é cunhado nas obras de Édouard Glissant na contraposição ao conceito de continente. $\mathrm{O}$ arquipélago estabelece o diverso enquanto o continente determina a unidade redutora.
} 
caribenho: depois do massacre generalizados dos seus povos autóctones, os países que o constituem foram alvo de outras colonizações.

Os arquipélagos são definidos como estes postos de vigia. Segundo Glissant:

E, se de pé, cada um em uma dessas ilhas, cada um no seu país, olhamos para o horizonte, vemos não um outro país apenas, mas o Caribe inteiro, que modifica o nosso olhar e lhe ensina a nada subestimar desse mundo. ${ }^{9}$

Os arquipélagos, a relação entre eles, permitem a visão do todo-mundo. Este é a totalidade realizada dos dados conhecidos e desconhecidos do universo. O todo-mundo é constituído dos arquipélagos, que por sua vez é formado por paisagens. As paisagens são como categorias do sendo, conduz para além de si-mesmo e faz conhecer o que está em nós. As paisagens vivem e morrem em nós e conosco. É possível você frequentar uma paisagem antes de ter ido a ela.

A discussão do pensamento arquipélago tem sua contraposição estabelecida pelo pensamento continente, que possui apenas uma paisagem como imagem. A distinção entre o continente e o arquipélago se dá na seguinte equação: “O pensamento continental, que desvela em diásporas os esplendores do Uno. Pensamento arquipelágico, onde se concentra a infinita variação da diversidade. Mas a aliança entre eles está ainda por vir”"

$\mathrm{O}$ pensamento de continente fundamentou a violência monocolonial e a perpetuação da violência contemporânea, entretanto, o pensamento de arquipélago estabelece a discussão acerca da identidade no pensamento de Glissant. A identidade deixa de ser mera permanência, mas é variável. O pensamento de identidade enquanto raiz (pensamento continente), forjada no mistério sagrado da raiz, busca o refúgio generalizante do universal enquanto valor. A identidade compreendida enquanto sistema de relação (pensamento arquipélago), como "dar-se com”, entende-se como, inversamente, uma forma de violência que contesta o universal generalizante e que tanto mais requer a severa exigência das especificidades.

A identidade pode ser resumida como a identidade-raiz (pensamento continente), fundada numa visão, num mito da criação do mundo. É santificada pela violência oculta de uma filiação, e ratificada pela pretensão à legitimidade, que permite a uma comunidade proclamar o seu direito à posse da terra, que se torna assim território. Também é preservada, através da projeção em outros territórios que se torna legítimo conquistar - e pelo projeto de um saber. A identidade-raiz fundamenta o pensamento de si e do território.

A outra possibilidade é a identidade-relação (pensamento arquipélago). Ela não está ligada a uma criação do mundo, mas a vivência contraditória e consciente dos contatos entre culturas. A identidade constitui-se na trama caótica da relação, e se afasta da

\footnotetext{
${ }^{9}$ GLISSANT, O pensamento do tremor. La cohée du Lamentin, p. 89.

${ }^{10}$ Ibidem, p. 219.
} 
violência oculta da filiação e da lógica da legitimidade. Não concebe a terra como um território, de onde se projete para outros territórios, mas um lugar onde as pessoas se dão em vez de se compreenderem. A identidade-relação exulta no pensamento da errância e da totalidade.

A identidade-raiz (pensamento continente) desenraizou o sagrado com o massacre das comunidades tradicionais. A partir dessa experiência a terra das Antilhas não podia tornar-se território, mas sim terra rizomada, errante. Segundo Glissant:

Enquanto absoluto enraizado, a terra da Martinica não pertence nem aos descendentes dos africanos deportados, nem aos békés, nem aos hindus, nem aos mulatos. Mas aquilo que era consequência da expansão europeia (o extermínio dos pré-colombianos, a importação de população novas) é precisamente aquilo que funda uma nova relação com a terra: não o absoluto sacralizado de uma posse ontológica, mas a cumplicidade relacional. ${ }^{11}$

Glissant é um autor que percorre as circunstâncias do mundo. E um dos conceitos apresentados que sustenta o movimento do arquipélago é a crioulização, o qual foge da noção de filiação e se aproxima da cumplicidade relacional. A crioulização é imprevisível, de acordo com Desportes, pois ela dialoga com o princípio da incerteza de Heisenberg e com a errância negro-africana, a fim de produzir o entendimento e a imagem da crioulização: "Si Glissant se montre aussi attentif à la relation d'incertitude de Heinsenberg, dont il se sert pour assurer le caractere d'imprévisibilité de la créolisation" ${ }^{12}$. É importante para o entendimento do pensamento do arquipélago a imagem da crioulização.

Os arquipélagos são imprevisíveis, heterogêneos, diversos. Os arquipélagos são lugares que se encontram por meio de múltiplas territorialidades, se interconectam sem a necessidade de códigos. São compostos de imaginários que atravessaram os oceanos. E esta multiplicidade de imaginários corresponde ao tremor imprevisível do todo-o-mundo.

O pensamento do arquipélago é engajado na diversidade originária, na crítica a genealogia e na multiplicidade comum. Glissant deslocou a perspectiva conceitual da ontologia da identidade. A ontologia da relação agora é a política do futuro, no pensamento de Glissant. E o arquipélago é fundamental para este entendimento, uma vez que ele não é simplesmente o espaço, pois primeiro é imaginário. Nesse sentido, a filosofia do arquipélago está inscrita na estética. O que mobiliza o pensamento no entendimento do arquipélago também é a paisagem.

\footnotetext{
${ }^{11}$ GLISSANT, Poética da Relação, p. 142.

${ }^{12}$ DESPORTES, La paraphilosophie D’Édouard Glissant, p. 19.
} 
As paisagens, no pensamento de Glissant, caracterizam a geopoética, isto é, uma poética do lugar, a cultura como localização que singulariza o lugar e possibilita o diálogo com o todo-mundo. No arquipélago está presente a discussão do território e do espaço.

O espaço da Martinica, assim como o brasileiro, é constituído de territórios. E, neste sentido, a produção literária, desde o arquipélago, consiste em inventar um povo que falta. A invenção difere da criação "na medida em que ela acrescenta ao criado uma intenção manifesta, um verdadeiro prolongamento de natureza, de certa forma um futuro incluído no presente" ${ }^{13}$. O povo inventado é sempre um devir povo. E esta invenção é o que falta à totalidade-mundo. O arquipélago é uma das possiblidades de diálogo com o Todo-omundo por ser um espaço constituído de narrativas, histórias e culturas. O arquipélago instaura a relação.

A relação não é sinônima de diluição e de ausência de agenciamentos. A filopoética da relação é o acontecimento do Todo-mundo. Este é o lugar da relação entre as zonas de vizinhanças, esta é um estado permanente e indiferenciado. A vizinhança é o lugar indefectível, ou incontornável e aberto. O Todo-o-mundo é "essa abertura, de lugar em lugar, todos igualmente legitimados, e cada um deles em vida e conexão com todos os outros, e nenhum deles redutível ao que quer que seja, é o que informa o Todo-o-Mundo” ${ }^{4}$.

O Todo-o-Mundo é o lugar de uma realidade em processo, a crioulização. Há um processamento das contrações de espaços e as precipitações de tempo e, por isso, os resultados são inesperados. $\mathrm{Na}$ discussão acerca do inesperado, Glissant encontra o diálogo com a filosofia, a arte e a literatura. Ele dialoga com Gilles Deleuze, sobre essa relação, pois não há mais urgência em delimitar estruturas onde nos é dado explorar processos.

A exploração dos processos, no que tange as abordagens do ser e do sendo, ou em detectar o real, significa aceitar um inaceitável, e isso é pensar, aprender a pensar o imprevisível. As opiniões de Deleuze e Guattari, por mais que sejam marginalizadas, constroem o corpo fluente de novas poéticas. Glissant questiona o que seria essa totalidade, o processo é ininterrupto. A intuição da multiplicidade, em Deleuze e Guattari, passa por indivíduos e especificidades. Nesse entido, "O rizoma é uma rede, uma alquimia também”15.

\section{Filopoética $^{16}$}

\footnotetext{
${ }^{13}$ GLISSANT, O pensamento do tremor. La cohée du Lamentin, p. 135.

${ }^{14}$ Ibidem, p. 136.

${ }^{15}$ Ibidem, p. 139.

${ }^{16}$ A discussão da filopoética no trabalho de Glissant está em diálogo com Manuel Norvat. Ver NORVAT, Le Chant du Divers. Introduction à la philopoétique d'Édouard Glissant, 2015.
} 
O encontro entre a filosofia e a poética, a qual denominamos de filopoética, é o lugar da renovação do imaginário. É a possiblidade do nascimento de outros imaginários, é a "recusa em morrer"17.

A filopoética, na sua relação paradoxal, tem a característica de se aproximar do todo, mas no mesmo instante se afasta das visões globais. É o diverso que lança a vertigem das multiplicidades, mas com a imagem do horizonte.

A filopoética busca reconstruir a memória. É uma poética histórica de disputa do imaginário. A memória e o esquecimento fazem parte do mesmo imaginário, por isso, a filopoética é um modo de imaginar e de acessar o imaginário do pensamento-mundo.

O imaginário dos povos caracterizados pela violência da colonização, a qual perpetua nos dias atuais pelo signo da necropolítica, é alimentado por alienações concretas. Na leitura de Jaime Amparo:

De acordo com Mbembe, a articulação entre velhas e novas formas de dominação está fazendo surgir uma nova forma de governamentalidade cuja característica principal é a sujeição da vida ao poder máximo da morte. Neste contexto de necropoder, alguns territórios ambientam a "topografia da crueldade" e algumas populações figuram como os marcados incondicionalmente como passíveis de serem mortos. Neste novo paradigma, a distribuição calculada da morte é o que configura a (necro)política moderna ${ }^{18}$.

A necropolítica é uma expressão do imaginário. As instituições se mobilizam em relação com os imaginários. Neste aspecto, a filopoética é uma postura de crítica ao imaginário racista. A importância de se produzir um pensamento afastado da perspectiva do imaginário da violência do racismo tem uma intenção ética.

O racismo é uma ferramenta de muita importância no regime necropolítico, na medida em que cria uma relação sem desejo. $\mathrm{Na}$ órbita do discurso da política de morte tem o terror e o horror como leitmotiv: o terror tem como objetivo construir o colapso na sociedade de direito, descontruindo as fontes das comunidades democráticas. Entretanto, o combate ao terror, às práticas anti-terrorista, constrói nas sociedades o estado de exceção, eles "conseguem combater inimigos sobre os quais a violência do Estado deveria poder desabar, sem qualquer restrição" 19 .

A crítica a violência do racismo se dá por meio do conteúdo e da forma. A concepção plural dos gêneros, tais como, poesia, ensaio e romance enfatiza a característica do diverso na forma a qual Glissant mobiliza seu pensamento. A crítica ao pensamento

\footnotetext{
${ }^{17}$ Referência ao livro de Achille Mbemb. Ver MBEMBE, África Insubmissa. Cristianismo, Poder e Estado na sociedade pós-colonial, 2013.

${ }^{18}$ AMPARO, Necropolítica racial: a produção espacial da morte na cidade de São Paulo, p. 6.

${ }^{19}$ MBEMBE, Políticas da Inimizade, p. 58.
} 
colonial tem que ser além do conteúdo, deve ser feita também a partir da forma. Segundo Norvat:

C’est que Glissant fait irruption dans la modernité littéraire. L’inclassable de as philopoétique (une posture dite "postcoloniale") lui fait considérer les mentions "roman" ou "poésie" sur les couvertures de ses livres comme pures conventions éditoriales qu'il n'a de cesse de renverser de l'intérieur; ce qui ne signifie pas pur autant qu'il soit complètement em dehors des problématiques ou états d'âme des écrivains de son temps: ceux du nouveau roman, de Butor, de Ponge, voire du "sistème" Sollers, par exemple ${ }^{20}$.

A crítica à violência epistêmica ${ }^{21}$ se dá de maneira efetiva através da forma, não apenas do conteúdo. O obstinado desejo da filosofia, dita universal, sem contexto e sem corpo, se dá em produzir uma filosofia que tenha como sentido um sonho enganador, o universal, sem paisagem, como isca. Deste modo, construindo um único imaginário, na lógica da aniquilação da alteridade.

A filopoética não é compreendida como uma essência, mas como uma atividade. $O$ ser humano é caracterizado em sua história universal, enquanto na poesia é o lugar do ser humano concreto e individual. A relação entre os paradoxos, não na tentativa de resolvêlos, mas de relacioná-los: unidade e multiplicidade, estrutura e singularidade, universal e contexto. A filósofa Maria Zambrano problematiza a relação da filosofia com a poesia:

La poesia perseguia, entre tanto, la multiplicidade deñada, la menospreciada heterogeneidade. El poeta enamorado de las coisas se apega a ellas, a cada uma de ellas y las sigue a través del labirinto del tempo, del cambio, ain poder renunciar a nada: ni a uma criatura ni aun instante e esa criatura, ni a uma partícula de la atmosfera que la envuelve, ni a um matiz de la atmosfera que la envuelve, ni a um matiz de la sombra que arroja, ni del perfume que expande, ni del fantasma que ya em ausência suscita. ? Es que acaso al poeta no e importa la unidad? ? Es que se queda apegado vagabundamente- inmoralmente a la multiplicidade aparente, por desgana y pereza, por falta de ímpetu ascético para perseguir es amada del filósofo: la unidad? $?^{22}$

A filosofia e a poesia trazem o conflito da heterogeneidade com a unidade. A filosofia tem o desejo obstinado da unidade, esta é a característica da dita violência filosófica. Enquanto o filósofo busca o uno, o poeta deseja a heterogeneidade. O poeta busca cada coisa em sua restrição. O poeta não tem como característica o obstinado desejo

\footnotetext{
${ }^{20}$ NORVAT, Manuel, Le Chant du Divers. Introduction à la philopoétique d'Édouard Glissant, p. 158.

${ }^{21}$ Alusão ao livro de Santiago Castro-Gómez. Ver CASTRO-GÓMEZ, Critica de la razón latino Americana, 2011.

${ }^{22}$ ZAMBRANO, Filosofia y poesia, p. 19.
} 
da questão conceitual do pensamento, mas a coisa inventada, sonhada, o que existe e o que não existe. A unidade presente na poesia é elástica. Ainda em diálogo com Zambrano, "Por eso la unidad a que el poeta aspira está tan lejos de la unidad hacia la que se lanza el filósofo. El filósofo quiere lo uno, sin más, por encima de todo”23.

O filósofo não abre mão da verdade, enquanto o poeta não crer na verdade, não nessa verdade da filosofia moderna ocidental, a qual estabelece a dicotomia da verdade e do engano, das coisas que são e as que não são. A verdade do poeta não é fundamentada no todo. O poeta tem sua verdade, mas não a verdade que cria a exclusão e persiste na dominação.

A filosofia consistiria na disputa pela verdade e pela unidade ${ }^{24}$. Sendo assim, a filosofia teria a unidade, a verdade e a ética. A ética pelo fato de ser esse encontro com o todo, a unidade, o universal. Todavia, o poeta não teria método nem ética. Pelo fato da poesia está acolhida pela multiplicidade e heterogeneidade.

Pode-se inferir que pensar na tensão da filopoética é estar imerso no imprevisível e no diverso utópico dos povos por vir. A filopoética é a utopia. Ela traz o entendimento de um conhecimento forjado pelas suas paisagens, pelo tremor e trepidação do mundo. Segundo Norvat ${ }^{25}$, a filopoética de Glissant é a tradução do seu perspectivismo, este é "um relativisme qui met em perspective toute pensée, tout sustème de pensée par rapport aux autres doctrines concorrentes" 26 .

Pode-se inferir que pensar na tensão da filopoética é ser imerso no imprevisível e no diverso utópico dos povos por vir. Na noção filopoética não se estabelece uma tensão entre a filosofia e a poesia.

La poétique de la relation est toujours ainsi une philosophie, et inversement: eles se préservent mutuellement des fausses finalités. Alors nous découvrons émerveillés que la langue des philosphies est d'abord celle du poème. ${ }^{27}$

O meio de expressão da filosofia é primeiro o do poema. A filopoética navega entre a visibilidade e o obscuro. A filosofia é uma poética. A poética acessa a verdade por meio do barulhamento e trepidação do mundo.

A filosofia é uma poética, porque é com a poética que se é possível acessar a diversidade infinita, a qual pode-se imaginar como unidade. A filopoética é o canto do diverso nos arquipélagos, a recusa aos sistemas pretensamente universais, que se apresentam sem contextos. Por isso, este pensamento segue na contramão da visão

\footnotetext{
${ }^{23}$ Ibidem, p. 24.

${ }^{24}$ Ibidem.

${ }^{25}$ NORVAT, Manuel, Le Chant du Divers. Introduction à la philopoétique d'Édouard Glissant, 2015.

${ }^{26}$ Ibidem, p. 13.

${ }^{27}$ GLISSANT, Philosophie de la Relation: poésie en étendue, p. 87.
} 
totalizante. Neste aspecto, o diverso é uma constante nesta perspectiva. O diverso em constante relação. O diverso não é o mesmo que estéril, ele significa uma relação transversal e não tem a transcendência universalista.

O diverso, a mundialidade, é uma categoria muito presente no entendimento da filopoética. No pensamento de Glissant, se relaciona a ciência e o sonho, a ficção e a utopia, o imaginário e o real. É a característica de um pensamento crioulo. A crioulização acolhe o paradoxo, não busca uma síntese entre o imaginário e o real ou a ciência e o sonho. Os elementos diversos são colocados em relação. Esta é a quantidade infinita de todas as particularidades do mundo. Neste sentido, a relação pode ser entendida como uma forma de universal que, no entanto, não busca a monotonia do mundo, que seria a mundialização, caracterizado como antidiverso. É um universal diverso, a mundialidade. No entanto, o combate a mundialização não se dá pela troca da palavra, mundialidade, mas pelo imaginário.

A mundialidade pode ser vista com a imaginação, entretanto, essa nova região do mundo, o todo-mundo, sempre escapa e se afasta. Mas um dos modos de conceber a totalidade-mundo é pelo imaginário, pois ele cria a realidade dos arquipélagos e das paisagens. E esta criatividade não busca verdade do todo, pois "rien n'est vrait tout est vivant" $^{28}$. O que é vivo mobiliza o ato poético e o ato político. A beleza que falta à vida convida o filósofo a uma viagem solitária (solidão existencial) e uma mobilização solidária do mundo (solidariedade poética).

A crítica e superação da violência, não se dará apenas produzindo conceito ou mudando os conteúdos. Criar conceitos, isso é necessário e urgente, todavia, além de criar conceitos, criar mundos, há de fecundá-los com a imaginação. Desta maneira, não se pensa apenas o mundo, mas se vive, experimenta ele e sente suas fragilidades.

A filosofia afro-diaspórica, na perspectiva do arquipélago e da filopoética, se caracteriza pelas alianças entre os diversos saberes. A filosofia não operaria como filiação, mas em relação com a literatura, educação, história, arte, geografia. Um outro aspecto é uma filosofia com o pensamento contextualizado. E a paisagem que totaliza a imagem dos arquipélagos diaspórico é o racismo. Filosofar desde os arquipélagos é um convite para uma luta contra as violências.

\section{Conclusão}

A relação entre a filosofia e a poesia provocam novas figuras do imaginário. Entretanto, essas figuras imaginárias são construídas a partir da imagem (paisagem) e do conceito. A paisagem (imagem) é papel da poesia, enquanto o conceito da filosofia. Todavia, o mundo não se encontra por inteiro no conceito ou na imagem (paisagem). É

\footnotetext{
${ }^{28}$ GLISSANT, Philosophie de la Relation: poésie en étendue, p. 106.
} 
necessário esse encontro paradoxal do universal com o particular para a instauração da inovação, do mesmo e do diverso, da inventividade, da beleza, da raiva e da busca pela floresta imaginária de resistência.

É importante não perder o destaque de que a poesia é a fonte de engajamento político do filósofo Glissant. A poesia é revolta e raiva. A poética é ao mesmo tempo a filosofia. O logos e o pathos estão relacionados, não estão dicotomizados. Entre a filosofia e poesia está a intenção ética deste trabalho, é o lugar da deriva, no nascedouro do inominável, inclassificável, da vertigem, da solidão, do desvio e da insurreição do imaginário.

O imaginário do racismo é uma fonte de muita importância para a atuação da violência. A perspectiva de raça sempre foi muito viva no pensamento ocidental. E o racismo retira os grupos humanos subjugados da partilha comum da humanidade, do Todo-o-mundo. A raça sempre atuou como uma imagem de muita força na filosofia política ocidental, precisamente no exercício do imaginário de desumanização e tiranização das populações fora do espaço ocidentalizado. Portanto, o imaginário forjado desde a filopoética segue no caminho de produção de imaginários de resistência da política de morte.

A guerra é em torno da disputa de paisagens. É uma guerra de imaginários. Para isso, busca o diálogo com os arquipélagos, as paisagens, os contextos e imagens de cada lugar com pretensões de relacionar-se com o todo-mundo.

Filosofar desde os arquipélagos impõem como exercício descolonial "estar à deriva na linguagem", como afirmou o poeta Edmilson Pereira ${ }^{29}$, por isso filopoética. A superação da violência se dará pela crítica dos conteúdos, mas pela reinvenção das formas. Os arquipélagos afrodescendentes podem ser interpretados como "índice de culturas em movimento"30.

E a partir desses índices se mobilizam uma cultura de vida contra a política de morte. A disputa pelo imaginário é um movimento importante para a manutenção da vida dos afrodescendentes.

O discurso sobre a origem, a pureza e a mistura todos são articuladores das experiências afrodescendente no Brasil. No entanto, como disse o poeta Edimilson Almeida Pereira, "Traído à vista do mar: pela origem. E o movimento de inversão se torna algo necessário e suficiente para continuar vivo, a ponto de trair se tornar um verbo totem"31.

\footnotetext{
${ }^{29}$ PEREIRA, E, p. 11.

${ }^{30}$ Ibidem, p. 77.

${ }^{31}$ Ibidem, p. 11.
} 


\section{Referências}

ALVES, Jaime Amparo. Necropolítica racial: a produção espacial da morte na cidade de São Paulo. Revista da Associação Brasileira de Pesquisadores/as Negros/as (ABPN), v. 1, n. 3, p. 89-114, fev. 2011. Disponível em: http://www.abpnrevista.org.br/revista/index.php/revistaabpn1/article/view/276>. Acesso em: 14 dez. 2018.

CASTRO-GÓMEZ, Santiago. Critica de la razón latino Americana. Bogotá: Editorial Pontificia Universidade Javeriano - Instituto Pensar - CONCIENCIAS, 2011.

CHANCÉ, Dominique. Édouard Glissant, um “traité du déparler”. Paris: Éditions Karthala, 2002.

DESPORTES, Georges. La paraphilosophie D'Édouard Glissant. Paris: L’Harmattan, 2008.

DURAND, Gilbert. O imaginário. Ensaio acerca das ciências e da filosofia da imagem. Rio de Janeiro: DIFEL, 1998.

FANON, Frantz. Os Condenados da Terra. Tradução Enilce Albergaria Rocha e Lucy Magalhães. Juiz de Fora: Editora UFJF, 2010.

FANON, F. Pele Negra, Máscara Brancas. Tradução de Renato da Silveira. Salvador: EDUFB, 2008.

GLISSANT, Édouard. Poética da Relação. Tradução de Manuela Ribeiro Sanches. Lisboa: Porto Editora, 2011.

GLISSANT, É. Philosophie de la Relation: poésie en étendue. Paris: Éditions Gallimard, 2009.

GLISSANT, É. Une nouvelle région du monde. Esthétque I. Paris: Éditions Gallimard, 2006.

GLISSANT, É. O pensamento do tremor. La cohée du Lamentin. Tradução de Enilce do Carmo Albergaria Rocha e Lucy Magalhães. Juiz de Fora: Gallimard/Editora UFJF, 2014.

LASOWSKI. Aliocha Wadl. Édouard Glissant, penseur des archipels. Paris: POCKET, 2015.

MBEMBE, Achille. Necropolítica: biopoder, soberania, estado de exceção, política da morte. Tradução Renata Santini. São Paulo: n-1 edições, 2018.

MBEMBE, A. Políticas da Inimizade. Tradução Marta Lança e Revisão L. Baptista Coelho. Lisboa: Antígona, 2017

MBEMBE, A. África Insubmissa. Cristianismo, Poder e Estado na sociedade pós-colonial. Tradução de Narrativa Traçada. Lisboa: Edições Pedago, 2013.

NORVAT, Manuel. Le Chant du Divers. Introduction à la philopoétique d'Édouard Glissant. Paris: L'Harmattan, 2015. 
PEREIRA, Edimilson de Almeida. E. São Paulo: Patuá, 2017.

ZAMBRANO, Maria. Filosofia y poesia. Mexico: FCE, 1996. 